\title{
SIGNIFICANCE OF STAY-GREEN TO FOSTER CROP PRODUCTION UNDER STRESS ENVIRONMENT - A MINI-REVIEW
}

\author{
Shantanu Das ${ }^{1 *}$, Nabarun Roy $^{2}$, Indrani Chakraborty ${ }^{3}$, Monoj Sutradhar ${ }^{4}$, Debojit Sarma ${ }^{1}$ \\ ${ }^{1}$ Department of Plant Breeding and Genetics, Assam Agricultural University, Jorhat, Assam, India \\ ${ }^{2}$ Department of Agricultural Biotechnology, Assam Agricultural University, Jorhat, Assam, India \\ ${ }^{3}$ Department of Plant Breeding and Genetics, CCS Haryana Agricultural University, Hisar, Haryana, India \\ ${ }^{4}$ Department of Agricultural Biotechnology, Bidhan Chandra Krishi Viswavidyalaya, Mohanpur, West Bengal, India
}

Received - January 19, 2018; Revision - March 29, 2018; Accepted - June 25, 2018

Available Online - August 10, 2018

DOI: http://dx.doi.org/10.18006/2018.6(4).639.651

\section{KEYWORDS \\ Stay-green \\ Extended foliar greenness \\ Drought \\ Chlorophyll catabolic enzymes \\ Grain filling stage.}

\begin{abstract}
An extended foliar greenness even under post-anthesis drought can be simply called as the stay-green phenotype. The maintenance of a balance between nitrogen $(\mathrm{N})$ demand and supply during grain filling stage is the key to stay-green phenotype. Chlorophyll catabolic enzymes (CCEs) are responsible for the degradation of chlorophyll. When a mutant disrupts the activity of these CCEs, it leads to stay-green phenotype. There are five classes of stay-green identified as A, B, C, D and E. The genotype possessing these traits can retain more photosynthetically active leaves under water shortages at the grain filling stage. Maintaining the greenness of leaves for longer time is the fundamental strategy for increasing crop yield and market value. Understanding the physiological and genetic basis of stay-green in relation to drought-resistance mechanisms are fundamental to the development of new strains that are better adapted to dry conditions.
\end{abstract}

* Corresponding author

E-mail: shanubrdr.oryza@gmail.com (Shantanu Das)

Peer review under responsibility of Journal of Experimental Biology and Agricultural Sciences.

Production and Hosting by Horizon Publisher India [HPI] (http://www.horizonpublisherindia.in/).

All rights reserved.
All the article published by Journal of Experimental Biology and Agricultural Sciences is licensed under a Creative Commons Attribution-NonCommercial 4.0 International License Based on a work at www.jebas.org.

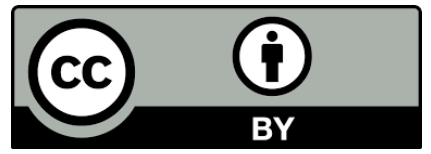




\section{Introduction}

Developing crops having high water use efficiency is one of the greatest challenges that crop scientists are facing today. The crops especially of semiarid origin such as millet and sorghum are found to possess critical adaptive mechanism which help them to escape and/or resist acute drought conditions. Maintaining the greenness of leaves for longer period is a principle strategy for increasing crop production, particularly under water-limited conditions (Abdelrahman et al., 2017). The pigment composition of plants is controlled by genetic and environmental stimuli and is the consequence of a balance between de novo synthesis and degradation (Barry, 2009). Stay-green is the ability of a plant to remain green and maintain photosynthesis for longer period of time, thereby contributing photosynthates for an extended time towards grain development (Borrell et al., 2001). Stay-green means heritable delayed yellowing or delayed foliar senescence in crop plant species (Thomas \& Howarth, 2000; Thomas \& Ougham, 2014), but this trait can actually be undesirable in certain circumstance when plants compete for resources (Antonietta et al., 2014). The stay-green phenotype is measured as green leaf area duration after anthesis, and is highly influenced by the time of anthesis, with earliness tending to give an increased duration for seed filling depending on environment condition (Gregersen et al., 2013).
Stay-green is categorized into two groups: one is 'functional staygreen' where plants photosynthesize for a longer period, which can result in higher yield; second is "non-functional/ cosmetic stay-green' where plants remain green due to lesions in chl catabolism, but lack photosynthetic competence (Hortensteiner, 2009; Tian et al., 2013). Due to its high importance, stay-green has been examined in many plants (rice, sorghum, barley, soybean, maize, wheat, french bean, tobacco, Arabidopsis, lettuce, broccoli, tomato and Capsicum etc.) which are being reviewed by Thomas \& Smart (1993) and Luche et al. (2015). The relationship of stay-green with useful traits such as greater number of fertile tillers (Ahlawat et al., 2008), higher number of grains/ear (Luche et al., 2017), tolerance to abiotic (Kassahun et al., 2010; VelascoArroyo et al., 2016) and biotic (Sun et al., 2017) stresses have been reported.

Mutants disrupting chlorophyll (chl) degradation, lead to staygreen phenotypes which ultimately enhance grain yield especially under water stressed environmental condition (Hortensteiner \& Krautler, 2011). Stay-green mutants have been categorized into five groups viz., A, B, C, D and E (Figure 1), using both temporal and biochemical characteristics (Thomas \& Howarth, 2000). Type A arises when leaves and stems prolongs their photosynthetic activity, experiencing a delay in plant senescence, but later senescence proceeds at a usual rate. Senescence in B type appears in normal way, but proceeds at relatively slow rate. Even though a

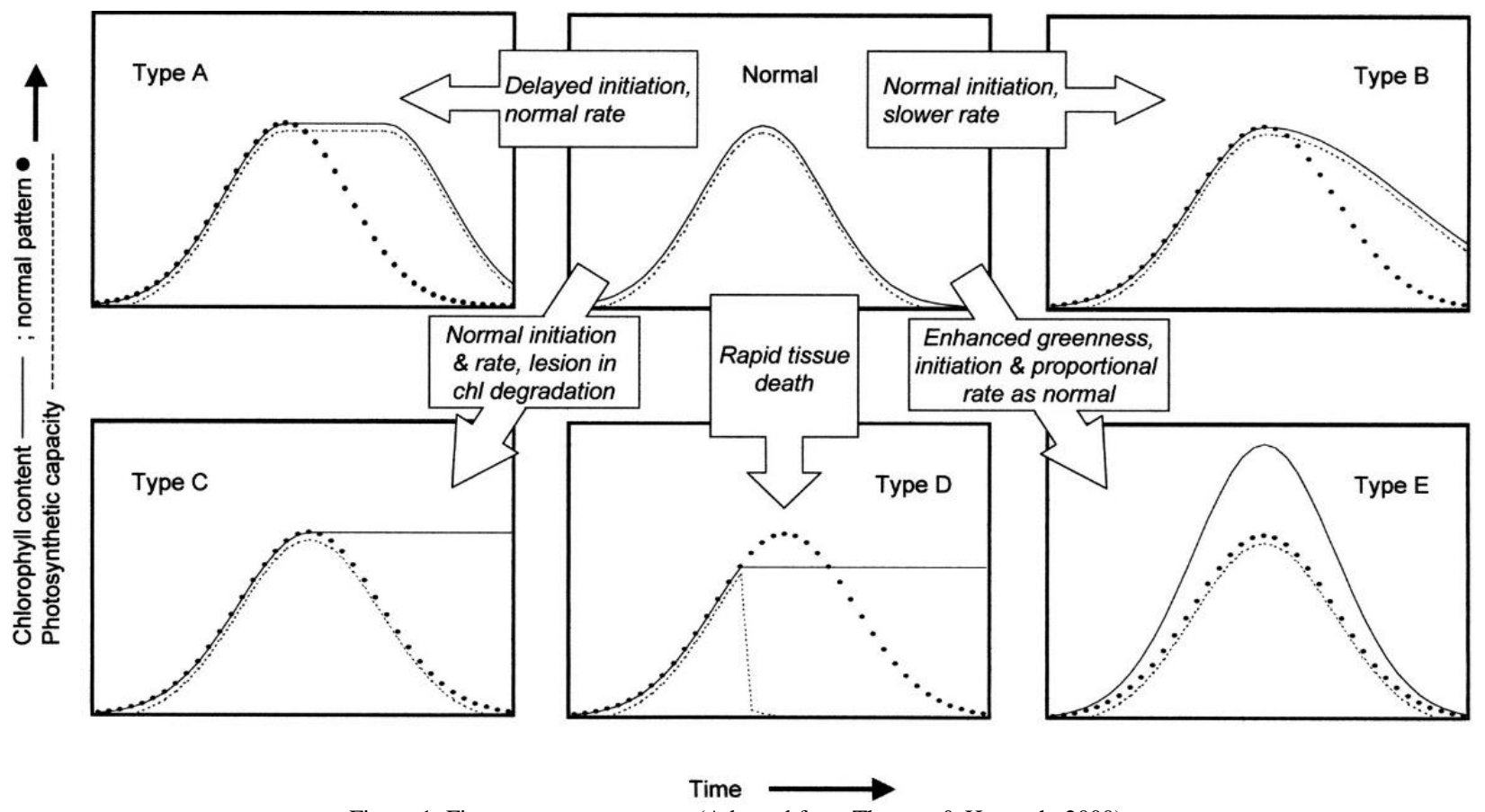

Figure 1: Five ways to stay-green. (Adopted from Thomas \& Howarth, 2000).

Journal of Experimental Biology and Agricultural Sciences

http://www.jebas.org 

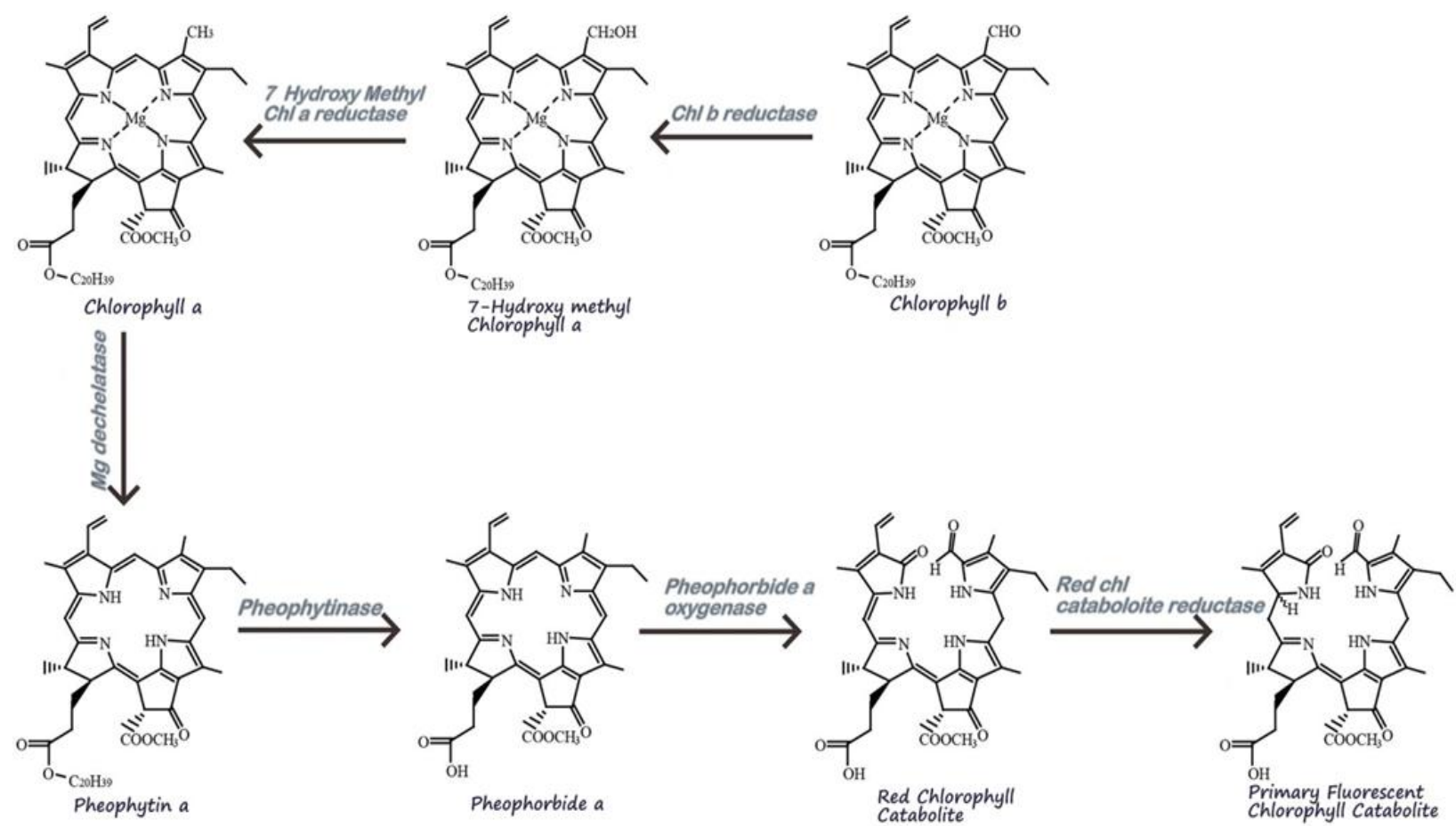

Figure 2: The chlorophyll degradation pathway

normal rate of senescence with declining photosynthetic activity follows in type $\mathrm{C}$ (cosmetic stay-green), the chl degradation pathway failure retains the greenness. In type D stay-green, green colour is retained forever due to killing of the leaf tissue by freezing, boiling or drying. Type $\mathrm{E}$ is due to highest accumulation of chl in photosynthetic tissues, results in delaying of senescence and maintains green tissue, even with the reduced ability of fixing $\mathrm{CO}_{2}$.

\section{Chl degradation pathway in higher plants}

Chl degradation is a highly controlled sequential process that converts fluorescent chl molecules into non-fluorescent catabolites, via a highly conserved multistep pathway termed as the 'PAO (pheophorbide $a$ oxygenase)' pathway, that are stored within vacuole (Figure 2). Chl degradation is of vital importance to plant development for its detoxifying activity of the phototoxicity of chl molecules once they are freed from their binding proteins (Li et al., 2017). In higher plants, there are two forms of chl molecules, chl $a$ and chl $b$, out of which chl $a$ is the degradable form. Chlorophyllide $a$, pheophorbide $a$, red chl catabolite and primary fluorescent chl catabolites are the intermediates responsible for this conversion. There are six types of CCEs encoded by chlorophyll catabolic genes (CCGs) involved in chl catabolism, viz. chlorophyll $b$ reductase (CBR), 7-hydroxymethyl chlorophyll a reductase (HCAR), $\mathrm{Mg}^{2+}$ dechelatase, pheophytinase (PPH), PAO and red chlorophyll catabolite reductase (RCCR) (Hortensteiner \& Krautler, 2011).
$\mathrm{Chl} b$ is synthesized from $\mathrm{Chl} a$ by oxygenation of its C-7 methyl group into a formyl group. In the degradation process of $\mathrm{Chl}, \mathrm{Chl}$ $b$ has to be converted to $\mathrm{Chl} a$, because chl derivatives with $\mathrm{C}-7$ formyl groups are not catalyzed in the later steps of chl degradation (Hortensteiner et al., 1995). The conversion of chl $b$ to chl $a$ proceeds by two successive reductions. The formyl group of chl $b$ is reduced by CBR to a hydroxymethyl group to produce 7-hydroxymethyl chlorophyll $a$. Then the reduction of 7-Hydroxymethyl chlorophyll $a$ by HCAR produces chl $a$. Mg from chl $a$ is then removed by $\mathrm{Mg}^{2+}$-dechelatase to convert chl $a$ to pheophytin $a$. The phytyl group of pheophytin $a$ is then hydrolyzed by PPH to produce pheophorbide $a$ and the tetrapyrrole ring structure of pheophorbide $a$ is opened by PAO, resulting in oxidized red chl catabolite (RCC), which is subsequently catalyzed by catabolite reductase RCCR to generate primary fluorescent chl catabolite (pFCC) (Krautler, 2016). This pFCC is further modified and transported into the vacuole where the acidic $\mathrm{pH}$ isomerize it to non-fluorescent products (Suzuki et al., 2005; Tanaka \& Tanaka, 2006; Balazadeh, 2014).

For the expression of stay-green, three steps in the chl degradation pathway is mainly known to be affected. Conversion of chl $b$ to chl $a$ is the first step in the pathway affected in which the activity of the CBR and HCAR are reduced to an extent that the greenness of the leaf remains unaffected. The second step to be affected is the conversion of pheophorbide $a$ into RCC by PAO enzyme (Hortensteiner, 2009). And the final step which is thought to be 
affected is the conversion of RCC to pFCC catalyzed by the enzyme RCCR. Change in the level of activity of these enzymes (downregulation) in the stay-green mutant is responsible for expression of the trait.

\section{The stay-green gene}

Defects in chl degradation are a cause of delayed leaf senescence. In many plant species, stay-green mutants have been identified that show retention of Chl during senescence. Mutations in NYC1 [(NON-YELLOW COLORING1) show such stay-green phenotypes in Arabidopsis and rice. CBR enzyme, a CCE is encoded by 2 isozyme genes NYC1 and NYC1-LIKE (NOL). $\mathrm{NYC1}$ expression has consistent correlation with leaf senescence (Kusaba et al., 2007). Rice or Arabidopsis NYC1 mutants exhibit a stay-green phenotype with high retention of light harvesting complex II (LHCII) subunits and Chl $b$ during senescence. An increasing number of natural or experimentally created stay-green mutants have been identified in plants such as bell pepper, tomato (Barry et al., 2008), rice(Park et al., 2007), Arabidopsis (Ren et al., 2007) termed as NON-YELLOWING 1 (NYE1)/ STAYGREEN1(SGR1) as well as Gregor Mendel's famous green cotyledon mutant of pea (Sato et al., 2007). Even though the functional activity of SGR proteins in $s g r$ missense mutants are critically dependent on several amino acid residues, but they may not affect the expression level of SGR genes (Barry et al., 2008). The SGR proteins are generally classified into two distinct subfamilies named as SGR and SGR-like (SGRL), both of which exist in both monocotyledonous and dicotyledonous plants (Barry, 2009). The Arabidopsis thaliana genome encodes 3 SGRs namely SGR1/NYE1, SGR2/NYE2 and SGRL. They contain a variable $\mathrm{N}$-terminal domain including the putative chloroplast transit peptide, a conserved central domain called the SGR domain, and a variable C-terminal region. A cysteine rich motif of unknown function is present in the C-terminal part of SGR which distinguishes it from SGRL proteins (Aubry et al., 2008). Shimoda et al. (2016) reported about the photosystem degradation capacity of NYE1/SGR1 during senecsence by producing a $\mathrm{Mg}^{2+}$ dechelatase that means the $\mathrm{CCE} \mathrm{Mg}^{2+}$-dechelatase is encoded by SGR1. The products of all these genes exert an important regulatory role in chl degradation during senescence, destabilizing protein-pigment complexes and increasing availability of chl for cleavage by CCEs (Qian et al., 2016). The physical interactions between CCEs and light-harvesting complexes (LHCs) is the main reason for degradation of Chl (Sakuraba et al., 2012). Sakuraba et al. (2014a) and Sakuraba et al. (2014b) also reported about the positive regulation (enhances leaf senescence) of Chl degradation by SGR1 and SGRL during senescence, whereas the process is negatively regulated (limits leaf senescence) by SGR2. SGRL is expressed in the developmental stage and catalyzes a reaction from chl $a$ and chlorophyllide $a$ to pheophytin $a$ and pheophorbide $a$, respectively, whereas SGR is expressed in the senescent stage and catalyzes a reaction only from chl $a$ to pheophytin $a$. Both subfamilies do not use chl $b$ as substrate. Chl $b$ tightly holds $\mathrm{Mg}$ (Saga \& Tamiaki, 2012), and SGR is thus not able to extract Mg from chl $b$. Conversion of chl $b$ to chl $a$ is thus important to loosen the $\mathrm{Mg}^{2+}$ and eventually the $\mathrm{Mg}$ is extracted by SGR. The overexpression of SGR1 in Arabidopsis resulted early leaf yellowing but the "STAY-GREEN" phenotype was expressed in sgrl mutants (Sakuraba et al., 2014a). On the contrary, SGR2 over expression resulted in "STAY-GREEN" phenotype whereas premature leaf senescence phenotype was expressed by by $s g r 2$ null mutants under both the dark and abiotic stress conditions in Arabidopsis. Expression of SGR1 is weak in pre-senescent leaves, but is induced during developmental and dark-induced senescence (Ren et al., 2007). SGR proteins from different species are highly similar and localize to the chloroplast's thylakoid membrane (Park et al., 2007). In Arabidopsis, the interaction between SGR1, six plastid-localized CCEs and LHCII proteins results in SGR1CCE-LHCII protein complexes required for chl degradation (Sakuraba et al. 2015). However, the binding affinity of SGR2 for CCEs is much lower than for SGR1 (Sakuraba et al. 2014b). So, the hetero-dimerization of SGR1 and SGR2 can obstruct SGR1 and CCEs interactions, limiting the SGR1-CCE-LHCII protein complex formation and finally chl degradation.

\section{Mechanism of stay-green trait}

In order to improve stay-green traits, understanding the mechanism of the traits has received much attention in plant science world. Chl content and level of photosynthetic activity of the leaves in water limiting conditions determines the expression of stay-green traits. Any mutation in the steps of chl biosynthesis and degradation pathway leads to expression of the trait.

\subsection{Carbon-Nitrogen Transition}

The Carbon (C)-capture phase of leaf function is succeeded by a phase of net organic $\mathrm{N}$ remobilization (Thomas \& Ougham, 2014). This C-N transitional period is actually the functional initiation of senescence and it is either delayed or runs slowly in functional stay-green (Thomas \& Howarth, 2000). Chl is made up of $\mathrm{C}, \mathrm{N}, \mathrm{Mg}$ and other constituents. Therefore, $\mathrm{C}: \mathrm{N}$ ratio is very important in the regulation of heat induced leaf senescence. For example, Borrell \& Hammer (2000) showed that senescent and stay-green sorghum hybrids are differed for $\mathrm{N}$ demand: supply balance, where stay-green having a shortfall in $\mathrm{N}$ that is about $25 \%$ lower than that in senescent hybrids, and explaining a slower rate of leaf senescence in the stay-green genotypes. Jespersen et al. (2015) reported about the improved protein level, photosynthesis and delayed senescence in creeping bent grass (Agrostis stolonifera) by spraying of carbonyldiamide as a source 
of $\mathrm{N}$. The stay-green expression can be considered as the equilibrium of $\mathrm{N}$ demand and supply during the stage of grain filling. The current research revealed that an increase in $\mathrm{N}$ uptake during grain filling maintain high photosynthetic activity in the leaves for longer period. Until and unless the $\mathrm{C}$ accumulation remains lesser than the sink capacity, prolonged photosynthesis keep on contributing $\mathrm{C}$ in crops by functional stay-green trait (Thomas \& Ougham, 2014).

\subsection{Chlorophyll Biosynthesis pathway}

Chl biosynthesis pathway can be divided into 4 phases (Hortensteiner, 2009; Figure 3). In the first phase, Glutamic acid is converted to 5-Aminolevulinic acid (ALA) in the presence of Glutamyl tRNA reductase (GluTR). Two molecules of ALA are condensed to form porphobilinogen (PBG). Again four $\mathrm{PBG}$ molecules are linked to form protoporphyrin IX, which converted into Monovinyl protochlorophyllide $a$ by the action of enzyme $\mathrm{Mg}^{2+}$-chelatase. A light dependent reaction takes place in the presence of NADPH and Protochlorophyllide oxidoreductase (POR) that lead to the formation of chlorophyllide. Attachment of phytol tail by the action of $\mathrm{Chl}$ synthetase completes the process by forming $\operatorname{chl} a$.

In this pathway, mainly two steps i.e. conversion of Glutamic acid to ALA and Monovinyl Protochlorophyllide $a$ to Chlorophyllide $a$ are influenced for the expression of stay-green trait (Thomas \& Ougham, 2014). In both the steps, the action of enzymes responsible for the conversion is over expressed or maintained for a longer period of time for the expression of stay-green phenotype.

\section{Relation of phyto-hormones with stay-green trait}

The initiation and progression of senescence in leaves involve complicated hormonal crosstalk (Kim et al., 2011 a; Khan et al., 2014; Kim et al., 2015; Schippers et al., 2015). Plant senescence is influenced by some major hormones such as Abscisic acid (ABA), Cytokinins (CKs), ethylene and strigolactones (SLs) which induces antagonistic and synergistic signaling effects (Thomas \& Ougham 2014). Leaf senescence is regulated by nuclear and chloroplast signals. Expression of senescence-associated transcription factors (TFs) are induced by positive and negative stimuli in the nucleus. Positive stimuli are ethylene, ABA, jasmonic acid (JA), salicylic acid (SA), brassinosteroids (BR), SLs, stress, dark and ageing, whereas the only negative stimuli are the CKs (Kusaba et al., 2013). "Positive TFs" induce the expression of senescence associated genes (SAGs) that promote leaf senescence whereas "negative TFs" induce SAGs that repress leaf senescence. Thus nucleus born senescence-associated TFs regulates chloroplast senescence. On the other hand, retention of chloroplast activity represses the expression of senescence inducible genes, indicating that signals from the chloroplast can regulate nuclear derived programs of senescence.

\subsection{Ethylene}

Ethylene acts as a positive regulator of senescence in ethylene insensitive 2 (EIN2) mutants by controlling the timing of leaf senescence (Pierik et al., 2006). The N-terminal transmembrane domain (a type of endoplasmic reticulum membrane-bound receptor), which includes ethylene response sensors (ERS1 and ERS2), ethylene response factors (ETR1 and ETR2) and ethylene

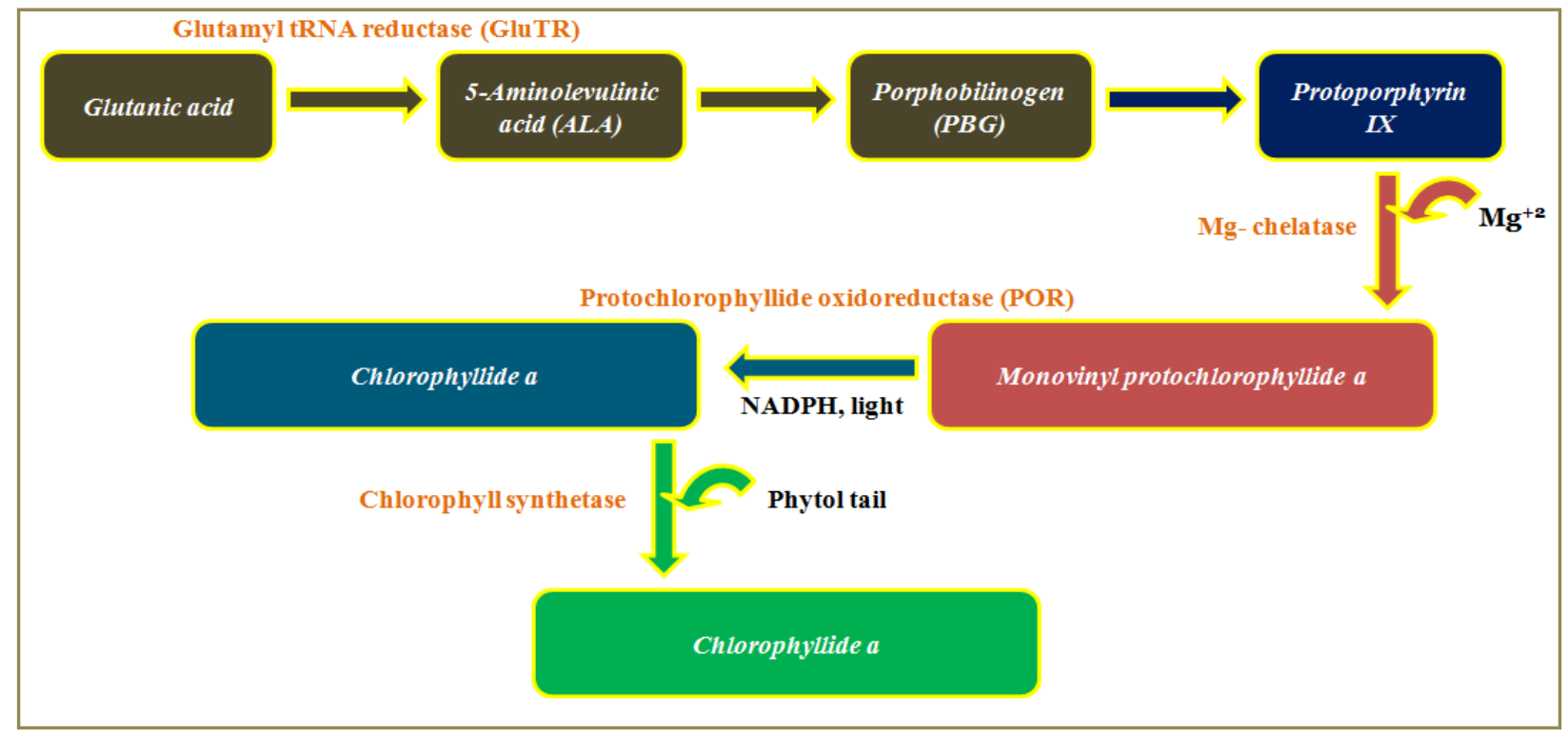

Figure 3: The chlorophyll biosynthesis pathway

Journal of Experimental Biology and Agricultural Sciences http://www.jebas.org 
insensitive factors (EIN2, EIN3 and EIN4) (Iqbal et al., 2017) perceive the ethylene induced signals. In the absence of ethylene, these ethylene receptors function redundantly, negatively regulating ethylene responses via direct binding to constitutive triple response1 (CTR1), which is a key negative regulator of the ethylene signal transduction pathway. Grbic' \& Bleecker (1995) observed that the leaves of etrl-1 mutants remain unresponsive to ethylene treatment and express stay-green phenotype. Even during leaf senescence, EIN2 and EIN3 mutants exhibit a severe staygreen phenotype. Li et al. (2013) also proved the positively regulation of EIN3 towards two important senescence regulatory genes ORE1 and NAP either directly or indirectly via negatively regulating miR164. Ethylene treatment may induce the expression of NYC1, NYE1 and PAO in Arabidopsis leaves but may repress them in ein3eill double mutant (Qiu et al. 2015). Yin et al. (2016) recently identified positive regulation of an ethylene responsive factor CitERF13, for CitPPH (a CCG gene) promoter during citrus fruit degreening.

\subsection{Abscisic Acid}

Senescing leaves are characterized by an increase in ABA levels which promotes chloroplast degradation (Xue-Xuan et al., 2010; Sah et al., 2016). ABA plays a dual role by repressing chloroplast biosynthesis genes and inducing genes that promote chl degradation during senescence. ABA positively regulates degreening during leaf senescence via an AtNAP-SAG113 (a PP2C family protein phosphatase) regulatory module which is involved in the movement of stomata (Zhang \& Gan, 2012). Lee et al. (2011) reported that prk1, an Arabidopsis mutant exhibited a stay-green phenotype during natural senescence, and was characterized by delayed senescence specifically in response to ABA among several senescence-inducing treatments. Liu et al. (2016a) found that after treatment with ABA, abigl (ABA Insensitive Growth 1, TF) mutants remain greener and produce more leaves than comparable wild-type (WT) plants, whereas when challenged with drought, abig1 mutants have fewer yellow, senesced leaves than WT. Conclusively, ABA induced by drought increases ABIG1 transcription which promotes leaf senescence and restricts new shoot growth.

Gao et al. (2016), three ABA responsive element (ABRE) binding TFs namely $\mathrm{ABF} 2, \mathrm{ABF} 3$ and $\mathrm{ABF} 4$ act as key regulators in mediating ABA-triggered chl degradation and leaf senescence in general in Arabidopsis.

\subsection{Jasmonic Acid}

JA is another plant hormone that modulates defense responses, growt hand development, and is also proposed to mediate leaf senescence (Kim et al., 2015). Many JA biosynthesis genes are differentially regulated, as some are up-regulated and others are down regulated in the progression of leaf senescence (He et al.,
2002). Exogenous application of JA on WT Arabidopsis promotes leaf senescence and induces the expression of several SAGs, including JA biosynthesis genes. Castillo \& Leon (2008) reported that a loss of function mutant of COI1 [encoding the co-receptor of JA and the antisense transgenic plant of 3-ketoacyl-CoA thiolase 2 (KAT2)] involved in JA synthesis have a stay-green phenotype in response to a dark incubation. In a recent study, Zhu et al. (2015) identified Arabidopsis MYC2/3/4 basic helix-loophelix proteins (the key JA signaling components) to direct transcriptional regulation of CCGs like PAO, NYE1 and NYC1 by binding to their promoters. Further, the PAO promoter activity was found to get enhanced by over expression of MYCs in Arabidopsis protoplasts and also by methyl jasmonate (MeJA) treatment in WT Arabidopsis plants. Though, the MYCs over expression lines showed accelerated leaf yellowing, the myc2myc3myc4 triple mutants showed a severe stay-green phenotype. These findings advocate that MYC2/3/4 proteins may directly activate CCGs for mediating JA-induced chl degradation.

\subsection{Cytokinin}

CKs are a class of hormones which has dominant adversary effect on senescence (Wilkinson et al., 2012; Zwack \& Rashotte, 2013). Kim et al. (2006) and Kim et al. (2012) reported that AHK3 and ARR2, which are components of CK signaling pathway, are constitutively expressed in Arabidopsis stay-green line ore12-1 (gain-of-function mutant) consequently supervening a stay-green phenotype. These reports unfold the influential contribution of AHK3 and ARR2 in the hormonal regulation of senescence. A wheat stay-green mutant tasg1 exhibited a significantly delayed senescence and high photosynthetic capacity than the WT plants, the examination of which revealed that concentration of soluble sugars were higher in the flag leaves and grains of tasg1 than in WT plant due to the altered metabolism and transport of soluble sugars regulated by CKs (Wang et al., 2016a; Wang et al., 2016b). Similarly, Yang et al. (2016) also reported an increased heat tolerance and grain yield in wheat cultivar "Wennong 6" (retaining the "STAY-GREEN" trait) with post anthesis CKs treatment.

Kim et al. (2011b) found that over expression of a gene (YUCCA6) coding for the rate-limiting enzyme of auxin synthesis (Indole 3 acetic acid- IAA) results in a stay-green phenotype. Based on microarray data from rice flag leaves during early senescence, Liu et al. (2016 b) identified W-box and G-box ciselements as positive regulators of senescence in the important rice variety Minghui 63 . The $\mathrm{W}$-box is the cognate cis-element for WRKY proteins, while the G-box is the cognate cis-element for bZIP, bHLH and NAC proteins. To investigate the potential relationship between flag leaf early senescence and hormone signaling, they surveyed the responses of TF genes to ABA, BR, $\mathrm{CK}$, auxin, JA and gibberellic acid (GA) using data from 
RiceXPro database. The result showed that the four TF families were affected by various hormones to varying degrees and also demonstrated that $\mathrm{ABA}, \mathrm{BR}$ and $\mathrm{CK}$-mediated signaling might converge on the same TFs. Zhang et al. (2016) reported that LpPPH gene [encoding pheophytin pheophorbide hydrolyase (PPH) that breaks down chl during leaf senescence in Lolium perenne L.] could be a direct downstream target of TFs in ABA and CK signaling pathways, as the breakdown could be regulated positively by ABA and ethylene, and negatively by CK.

\section{Breeding for stay-green trait}

Breeders have made great progress, supplying food to the growing human population through the release of more efficient cultivars, showing adaptation to environmental improvements such as irrigation and increased $\mathrm{N}$ input (Dias, 2015). However, the world population will be approximately 9.2 billion in 2050 (Jaggard et al., 2010) and to sufficiently feed all these people, the total food production will have to increase $60 \%$ to $70 \%$ (Tilman et al., 2011; FAO, 2012; Alexandratos \& Bruinsma, 2012; Pardey et al., 2014). Thus in the context of present agriculture situation where food demand is on the surge, and there is also menacing impact of global warming and extreme environmental desecration from professional agricultural operations, plant breeders are anticipating and devoting time not only to improve yield but also to select and specify foremost genotypes having outstanding productivity, through technical know-how of stress adaptation physiology (Araus et al., 2008).

Stay-green is characterized by delaying of leaf senescence in the last stage of plant maturity. Maintenance of grain filling for a longer period of time due to delayed senescence allows plants to accumulate greater photosynthates toward the end of maturation which result in the increase of grain size. In addition, association of stay-green with different biotic (Rosenow \& Clark 1981; Joshi et al., 2007) and abiotic stresses (Kassahun et al., 2010) has suggested potential for genetic improvement of several crops to promote stress tolerance and grain yield. However, breeding approaches are limited in the cases involving polygenic traits, significant environmental influences and low genetic variance. Genetic improvement for traits having high heritability is more effective. The stay-green trait is governed by only one gene having two alleles (Silva et al., 2001). The trait is positively heritable and controlled by four genes that are segregated independently, with strong contribution of additive effects (Joshi et al., 2007). Therefore, efficacious phenotypic selection and genetic manipulation for this trait will be most successful in early generations.

The stay-green genotypes in sorghum and wheat were reported have better grain filling in drought, high stem carbohydrate content, reduced lodging better grain weight and resistance to charcoal stem rot (McBee et al., 1983; Rosenow, 1984; Borrell et al., 2000a; Silva et al., 2001; Burgess et al., 2002). Greenness during the final stage of leaf development is an essential trait in increasing source strength in grain production. And reported that stay-green japonica rice 'SNU-SG1' had a good seed setting rate and grain yield (Yoo et al., 2007). Thus, the stay-green trait is considered as an important determinant of grain yield. For increasing grain yield, persistence of high photosynthetic capacity and efficient $\mathrm{N}$ remobilization at the time of grain filling are the principle factors (Gentinetta et al., 1986; Thomas \& Rogers, 1990; Rajcan \& Tollenaar, 1999; Yamaya et al., 2002; Spano et al., 2003; Abdelkhalik et al., 2005). Stay-green phenotype and related traits has been reported to enhance grain yield especially under post-anthesis drought conditions in wheat (Christopher et al., 2008; Adu et al., 2011; Bogard et al., 2011; Lopes \& Reynolds, 2012; Kipp et al., 2014; Christopher et al., 2016), sorghum (Xu et al., 2000; Borrell et al., 2000b; Borrell et al., 2012; Jordan et al., 2012; Borrell et al., 2014a; Borrell et al., 2014 b), maize (Bolanos \& Edmeades, 1996; Kamara et al., 2003; Zheng et al., 2009; Wang et al., 2012) and rice (Jiang et al., 2004; Hoang \& Kobata, 2009; Fu et al., 2009). Stay-green is thus widely honoured as a drought adaptation tool in cereals (Cattivelli et al., 2008; Gregersen et al, 2013). Thus, this association could be used as a basis for selection of high-yielding stay-green genotypes, especially for water-limited environments. Evangelista \& Tangonan (1990) reported about the good association of stay-green phenotype with resistance to stem rot in sorghum. Similar association was also reported by Joshi et al. (2007) with resistance to spot blotch in spring wheat. Some of the stay-green wheat cultivars viz. CN12, CN17 and CN18 from southwest China are high yielding and resistant to stripe rust (Luo et al. 2009). These are the clear evidences for the persistence of stay-green phenotype which can remain photosynthetically active even at the influences of various biotic stresses.

The improvement of stay-green phenotype is predicted to be much higher if information about the presence of stay-green genes/QTLs (quantitative trait loci) in the promising genotypes can be gathered with the help of linked molecular markers. QTLs studies in cereals have unveiled the value of functional stay-green in improving stress tolerance. Several QTLs associated with staygreen have been identified in different cereals like, fourteen QTLs (sg1.1.1, sg1.6.1, sg2.1.1, $\mathrm{sg} 2.1 .2, \quad \mathrm{sg} 2.2 .1, \quad \mathrm{sg} 2.3 .1, \quad \mathrm{sg} 2.5 .1$, $\mathrm{sg} 2.8 .1 \mathrm{sg} 3.1 .1, \mathrm{sg} 3.2 .1, \mathrm{sg} 3.5 .1, \mathrm{sg} 3.9 .1, \mathrm{sg} 4.1 .1$ and $\mathrm{sg} 4.2 .1)$ in maize (Zheng et al., 2009), four QTLs (StgB, Stg1, Stg3 and Stg4) in sorghum (Kassahun et al., 2010; Vadez et al., 2013), three QTLs (QSg.bhu-1A, QSg.bhu-3B and QSg.bhu-7D) in wheat (Kumar et al., 2010), six QTLs (csfl2/tcs2, tcs4, tcs5, csfl6, csfl9/tcs9 and csfl12) in rice (Fu et al., 2011) and ten QTL (HGSQ, HSPFLQ1, HSPFLQ2, HSPFL1Q, HLAUGQ1, HLAUGQ2, WGSQ, WGFL1Q1, WGFL1Q2, WLAUGQ) in 
barley (Gous et al., 2016) etc. The identified QTLs affecting staygreen may be a promising target for marker-assisted introgression of the functional stay-green trait into the breeding materials for yield improvement. Wang et al. (2018) recently fine mapped a stay-green mutant in Brassica campestris L. ssp. chinensis, which they termed "nye". Genetic analysis revealed that the stay-green trait is controlled by a single recessive gene, Brnyel. Using the BSA-seq method, a 3.0-Mb candidate region identified as the Brnyel gene was mapped on chromosome A03. They identified 12 genes in this region, 11 of which were annotated based on the B. rapa annotation database. They identified Bra019346, a homolog of the Arabidopsis AtNYE1gene, as a potential candidate gene responsible for the stay-green trait. It was supposed that characterization of this stay-green mutant and cloning of the staygreen gene will provide a foundation for unraveling the molecular mechanism of the stay-green trait in B. campestris L. ssp. chinensis.

Now-a-days, high-throughput phenotyping technologies like Greenseeker®, Phenomobile ${ }^{\circledR}, \quad$ ArduCrop ${ }^{\circledR}$ have allowed researchers to accurately select stay-green traits by using methods like Normalised Difference Vegetative Index (NDVI), Light Detection And Ranging (LiDAR), Single Photon Avalanche Diode (SPAD) etc (Kipp et al., 2014; Rebetzke et al., 2016). The most relevant phenotypic parameters in this regard, such as the deviations in leaf area, greenness and photosynthetic capacity can now be easily followed and documented thoroughly by utilizing these advanced machineries. Hence, a hefty breeding population also can be screened very easily and the most suitable (only the functionally active stay-green) germplasm can be selected precisely (Christopher et al., 2014).

\section{Ideotype of stay-green genotype}

To be an ideal stay-green genotype and to produce potential economic yield, genotypes are assumed to have some ideal characteristics especially under drought environmental condition. Firstly, spread and deep root system is important as it enable the plant to uptake more $\mathrm{N}$ to maintain active source-sink relationship during the grain filling stage. Moreover stay-green genotypes also have the ability to uptake more silicon from soil which reflected as lodging resistance (Kashiwagi et al., 2007; Luyckx et al., 2017). Genotypes with stay-green should exhibit a slow rate of chl degradation as it leads to prolong the duration of leaf senescence. As a consequence minimum chl content will be retained in the leaves for photosynthesis even during the period of senescence. The third assumption is that genotypes should have more total plant leaf area, so that the total green leaf area at the maturity stage will be more and it is an excellent indicator of stay-green. Thus, it is feasible to develop an ideal stay-green cultivar through pyramiding all these traits from potential sources using conventional or molecular breeding approaches.

\section{Conclusion}

During the last few years there have been tremendous increases in the understanding of the mechanisms and processes that control chl degradation in higher plants. Stay-green genotypes retained high photosynthetic competence, mesophyll conductance and photochemical efficiency as well as leaf chl content throughout grain filling as compared with other genotypes. From several findings, it has been suggested that a functional stay-green trait can be utilized for improving crop yield potential through the improved dry matter production during grain filling. There is a positive correlation between stay-green and yield as observed in several studies. Molecular techniques can be used to identify QTL controlling stay-green and its location in the chromosome. Finally it can be concluded that based on physiological, morphological and molecular characteristics, stay-green genotypes can be isolated and used in advanced breeding programmes for genetic crop improvement.

\section{Conflict of Interest}

The authors declare that there is no conflict of interest regarding the publication of this review paper.

\section{References}

Abdelkhalik AF, Shishido R, Nomura K, Ikehashi H (2005) QTLbased analysis of leaf senescence in an indica japonica hybrid in rice (Oryza sativa L.). Theoretical and Applied Genetics 110: 1226-1235.

Abdelrahman M, El-Sayed M, Jogaiah S, Burritt DJ, Tran LP (2017) The "STAY-GREEN" trait and phytohormone signaling networks in plants under heat stress. Plant Cell Reports 36:10091025 .

Adu MO, Sparkes DL, Parmar A, Yawson O (2011) 'Stay-green' in wheat: comparative study of modern bread wheat and ancient wheat cultivars. ARPN Journal of Agricultural and Biological Science 6: 16-24.

Ahlawat S, Chhabra AK, Behl RK and Bisht SS (2008) Genotypic divergence analysis for stay-green characters in Wheat (Triticumaestivum L. em.Thell). The South Pacific Journal of Natural Sciences 26: 73-81.

Alexandratos N, Bruinsma J (2012) World Agriculture towards 2030/2050: The 2012 Revision. Food and Agriculture Organization (FAO), Rome.

Antonietta M, Fanello DD, Acciaresi HA, Guiamet JJ (2014) Senescence and yield responses to plant density in stay-green and 
earlier-senescing maize hybrids from Argentina. Field Crops Research 155: 111-119.

Araus JL, Slafer GA, Royo C, Serret MD (2008) Breeding for yield potential and stress adaptation in cereals. Critical Reviews in Plant Science 27: 377-412.

Aubry S, Mani J, Hörtensteiner S (2008) Stay-green protein, defective in Mendel's green cotyledon mutant,acts independent and upstream of pheophorbide a oxygenase in the chlorophyll catabolic pathway. Plant Molecular Biology 67:243-256.

Balazadeh S (2014) Stay-green not always stays-green. Molecular Plant 7 :1264-6.

Barry CS (2009) The stay-green revolution: Recent progress in deciphering the mechanisms of chlorophyll degradation in higher plants. Plant Science 176: 325-333.

Barry CS, McQuinn RP, Chung MY, Besuden A, Giovannoni JJ (2008) Amino acid substitutions in homologs of the STAYGREEN protein are responsible for the green-flesh and chlorophyll retainer mutations of tomato and pepper. Plant Physiology $147: 179-87$.

Bogard M, Jourdan M, Allard V, Martre P, Perretant MR, Catherine Ravel C, Heumez E, Orford S, Snape J, Griffiths S, Gaju O, Foulkes J, Gouis J L (2011) Journal of Experimental Botany 62 (10): 3621-3636.

Bolanos J, Edmeades GO (1996) The importance of the anthesissilking interval in breeding for drought tolerance in tropical maize. Field Crops Research 48: 65-80.

Borrell A, Hammer G, Oosterom EV (2001) Stay-green: a consequence of the balance between supply and demand for nitrogen during grain filling? Annals of Applied Biology 138: 91-95.

Borrell A, Jordan D, Mullet J, Klein P, Klein R, Nguyen H, Rosenow D, Hammer G, Henzell R (2012) Discovering genes for drought adaptation in sorghum. In: Acquaah G, ed. Principles of plant genetics and breeding, $2^{\text {nd }}$ Ed. Oxford: Wiley-Blackwell, John Wiley \& Sons, 285-289.

Borrell AK, Hammer GL (2000) Nitrogen dynamics and the physiological basis of stay-green in sorghum. Crop Science 40: 1295-1307.

Borrell AK, Hammer GL, Douglas ACL (2000a) Does maintaining green leaf area in sorghum improve yield under drought? I. Leaf growth and senescence. Crop Science 40: 10261037.
Borrell AK, Hammer GL, Henzell RG (2000b) Does maintaining green leaf area in sorghum improve yield under drought? II. Dry matter production and yield. Crop Science 40: 1037-1048.

Borrell AK, Mullet JE, George-Jaeggli B, van Oosterom EJ, Hammer GL, Klein PE, Jordan DR (2014a) Drought adaptation of stay-green cereals associated with canopy development, leaf anatomy, root growth and water uptake. Journal of Experimental Botany 65: 6251-6263.

Borrell AK, van Oosterom EJ, Mullet JE, George-Jaeggli B, Jordan DR, Klein PE, Hammer GL (2014b) Stay-green alleles individually enhance grain yield in sorghum under drought by modifying canopy development and water uptake patterns. New Phytologist $203:$ 817-30.

Burgess MG, Rush CM, Piccinni G, Schuster G (2002) Relationship between charcoal rot, the stay-green trait, and irrigation in grain sorghum. Phytopathology 92: S10.

Castillo M, Leon J (2008) Expression of the beta-oxidation gene3ketoacyl-CoA thiolase 2 (KAT2) is required for the timelyonset of natural and dark-induced leaf senescence in Arabidopsis. Journal of Experimental Botany 59:2171-2179.

Cattivelli L, Rizza F, Badeck FW, Mazzucotelli E, Mastrangelo AM, Francia E, Marè C, Tondelli A, Stanca AM (2008) Drought tolerance improvement in crop plants: an integrated view from breeding to genomics. Field Crops Research 105: 1-14.

Christopher JT, Christopher, MJ, Borrell AK, Fletcher S, Chenu K (2016) Stay-green traits to improve wheat adaptation in wellwatered and water-limited environments. Journal of Experimental Botany 67: 5159-5172.

Christopher JT, Manschadi AM, Hammer GL, Borrell AK (2008) Developmental and physiological traits associated with high yield and stay-green phenotype in wheat. Australian Journal of Agricultural Research 59:354-364.

Christopher JT, Veyradier M, Borrell AK, Harvey G, Fletcher S, Chenu K (2014) Phenotyping novel stay-green traits to capture genetic variation in senescence dynamics. Functional Plant Biology 41: 1035-1048.

Dias JCS (2015) Plant Breeding for Harmony between modern agriculture production and the environment. Agricultural Sciences 6: 87-116.

Evangelista, CC, Tangonan, NG (1990) Reaction of 31 nonsenescent sorghum genotypes to stalk rot complex in Southern Philippines. Tropical Pest Management 36: 214-215. 
FAO (2012) How to Feed the World in 2050. FAO, Rome.

Fu JD, Yan YF, Kim MY, Lee SH, Lee BW (2011) Populationspecific quantitative trait loci mapping for functional stay-green trait in rice (Oryza sativa L.) Genome 54: 235-243.

Fu JD, Yan YF, Lee BW (2009) Physiological characteristics of a functional stay-green rice "SNU-SG1" during grain-filling period. Journal of Crop Science and Biotechnology 12: 47-52.

Gao S, Gao J, Zhu X, Song Y, Li Z, Ren G, Zhou X, Kuai B (2016) ABF2, ABF3, and ABF4 Promote ABA-Mediated Chlorophyll Degradation and Leaf Senescence by Transcriptional Activation of Chlorophyll Catabolic Genes and SenescenceAssociated Genes in Arabidopsis. Molecular Plant 9 :1272-1285.

Gentinetta E, Ceppi D, Lepori C, Perico G, Motto, M, Salamini, F (1986) A major gene for delayed senescence in maize: Pattern of photosynthates accumulation and inheritance. Plant Breeding 97: 193-203.

Gous PW, Hickey L, Christopher JT, Franckowiak J, Fox GP (2016) Discovery of QTL for stay-green and heat-stress in barley (Hordeum vulgare) grown under simulated abiotic stress conditions. Euphytica 207: 305-317.

Grbic V, Bleecker AB (1995) Ethylene regulates the timing of leaf senescence in Arabidopsis. The Plant Journal 8: 595-602.

Gregersen PL, Culetic A, Boschian L, Krupinska K (2013) Plant senescence and crop productivity. Plant Molecular Biology 82: 603-22.

He Y, Fukushige H, Hildebrand DF, Gan S. (2002) Evidence supporting a role of jasmonic acid in Arabidopsis leaf senescence. Plant Physiology 128: 876-884.

Hoang TB, Kobata T (2009) Stay-green in rice (Oryza sativa L.) of drought-prone areas in desiccated soils. Plant Production Science 12:397-408.

Hortensteine S (2009) Stay-green regulates chlorophyll and chlorophyll-binding protein degradation during senescence. Trends in Plant Science 14 :155-62.

Hortensteiner S, Krautler B (2011) Chlorophyll breakdown in higher plants. Biochimica et Biophysica Acta 1807 : 977-88.

Hortensteiner S, Vicentini F, Matile P (1995) Chlorophyll breakdown in senescent cotyledons of rape, Brassica napus L.: enzymatic cleavage of phaeophorbide a in vitro. New Phytologist $129: 237-246$.
Iqbal N, Khan NA, Ferrante A, Trivellini A, Francini A, Khan MIR (2017) Ethylene Role in Plant Growth, Development and Senescence: Interaction with Other Phytohormones. Frontiers in Plant Science 8:475.

Jaggard KW, Qi AM, Ober ES (2010) Possible Changes to Arable Crop Yields by 2050. Philosophical Transactions of the Royal Society B: Biological Sciences 365: 2835-2851.

Jespersen D, Yu J, Huang B (2015) Metabolite responses to exogenous application of nitrogen, cytokinin, and ethylene inhibitors in relation to heat-induced senescence in creeping bentgrass. PloS one 10 : e0123744.

Jiang GH, He YQ, Xu CG, Li XH, Zhang Q (2004) The genetic basis of stay-green in rice analyzed in a population of doubled haploid lines derived from an indicabyjaponica cross. Theoretical and Applied Genetics 108: 688-698.

Jordan DR, Hunt CH, Cruickshank, AW, Borrell AK, Henzell RG (2012) The relationship between the stay-green traits and grain yield in elite sorghum hybrids and grown in a range of environments. Crop Science 52: 1153-1161.

Joshi AK, Kumari M, Singh VP, Reddy CM, Kumar S, Rane J, Chand R (2007) Stay-green trait: variation, inheritance and its association with spot blotch resistance in spring wheat (Triticumaestivum L.). Euphytica 153: 59-71.

Kamara AY, Menkir A, Badu-Apraku B, Ibikunle O (2003) Reproductive and stay-green trait responses of maize hybrids, improved open-pollinated varieties and farmers' local varieties to terminal drought stress. Maydica 48:29-37.

Kashiwagi T, Hirotsu N, Madoka Y, Ookawa T, Ishimaru K (2007) Improvement of resistance to bending-type lodging in rice (Oryza sativa). Japanese Journal of Crop Science 76:1-9.

Kassahun B, Bidinger FR, Hash CT, Kuruvinashetti MS (2010) Stay-green expression in early generation sorghum [Sorghum bicolor (L.)Moench] QTL introgression lines. Euphytica 172 : 351-362.

Khan M, Rozhon W, Poppenberger B (2014) The role of hormones in the aging of plants - a mini-review. Gerontology 60 : 49-55.

Kim HJ, Ryu H, Hong SH, Woo HR, Lim PO, Lee IC, Sheen J, Nam HG, Hwang I (2006) Cytokinin-mediated control of leaf longevity by AHK3 through phosphorylation of ARR2 in Arabidopsis. Proceedings of the National Academy of Sciences, USA 103: 814-819. 
Kim J, Chang C, Tucker ML (2015) To grow old: regulatory role of ethylene and jasmonic acid in senescence. Frontiers in Plant Science 6:20.

Kim JH, Chung KM, Woo HR (2011 a) Three positive regulators of leaf senescence in Arabidopsis, ORE1, ORE3 and ORE9, play roles in crosstalk among multiple hormone-mediated senescence pathways. Genes \& Genomics 33: 373-381.

Kim JI, Murphy AS, Baek D, Lee SW, Yun DJ, Bressan RA, Narasimhan ML (2011 b) YUCCA6 over-expression demonstrates auxin function in delaying leaf senescence in Arabidopsis thaliana. Journal of Experimental Biology 62: 3981-3992.

Kim K, Ryu H, Cho Y-H, Scacchi E, Sabatini S, Hwang I (2012) Cytokinin facilitated proteolysis of ARABIDOPSIS RESPONSE REGULATOR 2 attenuates signaling output in two-component circuitry. The Plant Journal 69: 934-945.

Kipp S, Mistele B, Schmidhalter U (2014) Identification of staygreen and early senescence phenotypes in high-yielding winter wheat, and their relationship to grain yield and grain protein concentration using high throughput phenotyping techniques. Functional Plant Biology 41:227-235.

Krautler B (2016) Breakdown of chlorophyll in higher plantsphyllobilins as abundant, yet hardly visible signs of ripening, senescence, and cell death. Angewandte Chemie International Edition in English 55: 4882-907.

Kumar U, Joshi AK, Kumari M, Paliwal R, Kumar S, Roder MS (2010) Identification of QTLs for stay-green trait in wheat (Triticum aestivum L.) in the 'Chirya 3' × 'Sonalika' population. Euphytica 174: 437-445.

Kusaba M, Ito H, Morita R, Iida S, Sato Y, Fujimoto M, Kawasaki S, Tanaka R, Hirochika H, Nishimura M, Tanaka A (2007) Rice NON-YELLOW COLORING1 is involved in lightharvesting complex II and grana degradation during leaf senescence. Plant Cell 19 : 1362-1375.

Kusaba M, Tanaka A, Tanaka R (2013) Stay-green plants: what do they tell us about the molecular mechanism of leaf senescence. Photosynthesis Research 117: 221-234.

Lee IC, Hong SW, Whang SS, Lim PO, Nam HG, Koo JC (2011) Age-dependent action of an ABA-inducible receptor kinase, RPK1, as a positive regulator of senescence in Arabidopsis leaves. Plant Cell Physiology 52: 651-62.

Li Z, Peng J, Wen X, Guo H (2013) ETHYLENE-INSENSITIVE 3 isa senescence-associated gene that accelerates age-dependent leaf senescenceby directly repressing miR164 transcription in Arabidopsis. Plant Cell 25: 3311-3328.

Li Z, Wu S, Chen J, Wang X, Gao J, Ren G, Kuai B (2017) NYEs/SGRs-mediated chlorophyll degradation is critical for detoxification during seed maturation in Arabidopsis. Plant Journal 92:650-661.

Liu T, Longhurst AD, Talavera-Rauh F, Hokin SA, Barton MK (2016 a) The Arabidopsis transcription factor ABIG1 relays ABA signaled growth inhibition and drought induced senescence. Elife 5:e13768.

Liu L, Xu W, Hu X, Liu H, Lin, Y (2016 b) W-box and G-box elements play important roles in early senescence of rice flag leaf. Science Report 6: 20881.

Lopes MS, Reynolds MP (2012) Stay-green in spring wheat can be determined by spectral reflectance measurements (normalized difference vegetation index) independently from phenology. Journal of Experimental Botany 63: 3789-3798.

Luche HS, Silva JAG, Maia LC, Oliveira AC (2015) Stay-green: a potentiality in plant breeding. Ciencia Rural 45: 1755-1760.

Luche HS, Silva JAG, Nornberg R, Hawerroth MC, Silveira SFS, Caetano VR, Santos RL, Figueiredo, RG, Maia LC, Oliveira, AC (2017) Stay-green character and its contribution in Brazilian wheats. Ciencia Rural 47: e20160583.

Luo P, Zhang H, Shu K, Wu X, Zhang H, Ren Z (2009) The physiological genetic effects of 1BL/1RS translocatedchromosome in "stay-green" wheat cultivar CN17. Canadian Journal of Plant Science 89: 1-10.

Luyckx M, Hausman JF, Lutts S, Guerriero G (2017) Silicon and Plants: Current Knowledge and Technological Perspectives. Frontiers in Plant Science 23: 411.

McBee GG, Waskom RM, Miller FR, Creelman RA (1983) Effect of senescence and nonsenescence on carbohydrates in sorghum during late kernel maturity states. Crop Science 23: 372-376.

Pardey PG, Beddow JM, Hurley TM, Beatty TKM, Eidman VR (2014) A Bounds Analysis of World Food Futures: Global Agriculture Through to 2050. Australian Journal of Agricultural and Resource Economics 58: 571-589.

Park SY, Yu JW, Park JS, Li J, Yoo SC, Lee NY, Lee SK, Jeong SW, Seo HS, Koh HJ, Jeon JS (2007) The senescence-induced stay-green protein regulates chlorophyll degradation. The Plant Cell 19: 1649-1664. 
Pierik R, Tholen D, Poorter H, Visser EJ, Voesenek LA (2006) The Janus face of ethylene: growth inhibition and stimulation. Trends Plant Science 11: 176-183.

Qian L, Voss-Fels K, Cui Y, Jan HU, Samans B, Obermeier C, Qian W, Snowdon RJ (2016) Deletion of a Stay-Green Gene Associates with Adaptive Selection in Brassica napus. Molecular Plant $9: 1559-1569$.

Qiu K, Li Z, Yang Z, Chen J, Wu S, Zhu X, Gao S, Gao J, Ren G, Kuai B, Zhou X (2015) EIN3 and ORE1accelerate degreening during ethylene-mediated leaf senescence by directly activating chlorophyll catabolic genes in Arabidopsis. PLoS Genetics 11:e1005399.

Rajcan I, Tollenaar M (1999) Source: sink ratio and leaf senescence in maize: I. Dry matter accumulation and partitioning during grain filling. Field Crops Research 60: 245-253.

Rebetzke GJ, Jimenez-Berni JA, Bovill WD, Deery DM, James RA (2016) High-throughput phenotyping technologies allow accurate selection of stay-green. Journal of Experimental Botany 67: 4919-24.

Ren G, An K, Liao Y, Zhou X, Cao Y, Zhao H, Ge X, Kuai B (2007) Identification of a novel chloroplast protein AtNYE1 regulating chlorophyll degradation during leaf senescence in Arabidopsis. Plant Physiology 144: 1429-1441.

Rosenow DT (1984) Breeding for resistance to root and stalk rot in Texas. In: Mughogho LK (Ed.) sorghum root and stalk diseases: A critical review. Proceedings of the consultative discussion of research needs and strategies for control of sorghum root and stalk diseases: International Crops Research Institute for the Semi-Arid Tropics, (ICRISAT), Patancheru, India, pp. 209-217.

Rosenow DT, LE Clark (1981) Drought tolerance in sorghum. In: Drought tolerance in sorghum. Proceedings of the $36^{\text {th }}$ annual corn and sorghum research conference. Pp. 18-31.

Saga Y, Tamiaki H (2012) Demetalation of chlorophyll pigments. Chemistry \& Biodiversity 9: 1659-1683.

Sah SK, Reddy KR, Li J (2016) Abscisic acid and abiotic stress tolerance in crop plants. Frontiers in Plant Science 7: 571.

Sakuraba Y, Kim D, Kim YS,Hörtensteiner S, Paek NC (2014a) Arabidopsis STAYGREEN-LIKE (SGRL) promotes abioticstressinduced leaf yellowing during vegetative growth. FEBS Letters 588:3830-3837.

Sakuraba Y, Park SY, Kim YS, Wang SH, Yoo SC, Hörtensteiner S, Paek NC (2014b) Arabidopsis STAY-GREEN2 is a negative regulator of chlorophyll degradation during leaf senescence. Molecular Plant 7:1288-1302

Sakuraba Y, Park SY, Paek NC (2015) The divergent roles of STAY-GREEN (SGR) homologs in chlorophyll degradation. Molecules and Cells 38: 390-5.

Sakuraba Y, Schelbert S, Park SY, Han SH, Lee BD, Andres CB, KesslerF, Hörtensteiner S, Paek NC (2012) STAY-GREEN andchlorophyll catabolic enzymes interact at light-harvesting complexII for chlorophyll detoxification during leaf senescence in Arabidopsis. Plant Cell 24 : 507-518.

Sato Y, Morita R, Nishimura M, Yamaguchi H, Kusaba M (2007) Mendel's green cotyledon gene encodes a positive regulator of the chlorophyll-degrading pathway. Proceeding of National Academy of Sciences 104: 14169-14174.

Schippers JH, Schmidt R, Wagstaff C, Jing HC (2015) Living to Die and Dying to Live: The Survival Strategy behind Leaf Senescence. Plant Physiology 169 : 914-30.

Shimoda Y, Ito H, Tanaka A (2016) Arabidopsis STAY-GREEN, Mendel's Green Cotyledon Gene, Encodes MagnesiumDechelatase. Plant Cell 28: 2147-2160.

Silva SA, de Carvalho FIF, da R Caetano V, de Oliveira AC, de Coimbra JLM, de Vasconcellos N JS Lorencetti C (2001) Genetic Basis of Stay-green Trait in Bread Wheat. Journal of New Seeds 2 : 55-68.

Spano G, Di Fonzo N, Perrotta C, Platani C, Ronga G, Lawlor DW, Napier JA, Shewry PR (2003) Physiological characterization of 'stay-green' mutants in durum wheat. Journal of Experimental Botany 54: 1415-1420.

Sun L, Wang Y, Liu LL, Wang C, Gan T, Zhang Z, Wang Y, Wang D, Niu M, Long W, Li X, Zheng M, Jiang L, Wan J (2017) Isolation and characterization of a spotted leaf 32 mutant with early leaf senescence and enhanced defense response in rice. Scientific Reports 7: 41846.

Suzuki T, Kunieda T, Murai F, Morioka S, Shioi Y (2005) Mgdechelation activity in radis cotyledons with artificial and native substrates, Mg-chlorophyllin $a$ and chlorophyllide $a$. Plant Physiology and Biochemistry 43: 459-464.

Tanaka A, Tanaka R (2006) Chlorophyll metabolism. Current Opinion in Plant Biology 9: 248-255.

Thomas H, Howarth CJ (2000) Five ways to stay-green. Journal of Experimental Botany 51: 329-337.

Thomas H, Ougham H (2014) The stay-green trait. Journal of Experimental Botany 65: 3889-900. 
Thomas H, Rogers LJ (1990) Turning over an old leaf. University of Wales Review Science and Technology 6: 29-38.

Thomas H, Smart CM (1993) Crops that stays green. Annals of Applied Biology 123: 193-219.

Tian F, Gong J, Zhang J, Zhang M, Wang G, Li A, Wang W (2013) Enhanced stability of thylakoid membrane proteins and antioxidant competence contribute to drought stress resistance in the tasg1 wheat stay-green mutant. Journal of Experimental Botany 64: 1509-20.

Tilman D, Balzer C, Hill J, Befort BL (2011) Global Food Demand and the Sustainable Intensification of Agriculture. Proceedings of the National Academy of Sciences of the United States of America 108: 20260-20264.

Vadez V, Deshpande S, Kholova J, Ramu P, Hash CT (2013) Molecular breeding for stay-green: progress and challenges in sorghum. In: Translational genomics for crop breeding: abiotic stress, yield and quality. Wiley Inc., Pp. 125-141.

Velasco-Arroyo B, Diaz-Mendoza M, Gandullo J, GonzalezMelendi P, Santamaria ME, Dominguez-Figueroa JD, Hensel G, Martinez M, Kumlehn J, Diaz I (2016) vPap-1 C1A protease actively participates in barley proteolysis mediated by abiotic stresses. Journal of Experimental Botany 67: 4297-4310.

Wang AY, Li Y, Zhang C (2012) QTL mapping for stay-green in maize (Zea mays). Canadian Journal of Plant Science 92: 249256.

Wang N, Liu Z, Zhang Y, Li C, Feng H (2018) Identification and fine mapping of a stay-green gene (Brnye1) in pakchoi (Brassica campestris L. ssp. chinensis). Theoretical and Applied Genetics 131:673-684.

Wang W, Hao Q, Tian F, Li Q, Wang W (2016a) Cytokininregulated sucrose metabolism in stay-green wheat phenotype. PLoS One 11: e0161351.

Wang W, Hao Q, Tian F, Li Q, Wang W (2016b) The stay-green phenotype of wheat mutant tasg1 is associated with altered cytokinin metabolism. Plant Cell Reports 35: 585-599.

Wilkinson S, Kudoyarova GR, Veselov DS, Arkhipova TN, Davies WJ (2012) Plant hormone interactions: innovative targets for crop breeding and management. Journal of Experimental Botany 63: 3499-509.

Xu W, Rosenow DT, Nguyen HT (2000) Stay-green trait in grain sorghum: Relationship between visual rating and leaf chlorophyll concentration. Plant Breeding 119: 365-367.
Xue-Xuan X, Hong-Bo S, Yuan-Yuan M, Gang X, Jun-Na S, Dong-Gang G, Cheng-Jiang R (2010) Biotechnological implications from abscisic acid (ABA) roles in cold stress and leaf senescence as an important signal for improving plant sustainable survival under abiotic-stressed conditions. Critical Reviews in Biotechnology 30: 222-30.

Yamaya T, Obara M, Nakajima H, Sasaki S, Hayakawa T (2002) Genetic manipulation and quantitative-trait loci mapping for nitrogen recycling in rice. Journal of Experimental Botany 53: 917-925.

Yang D, Li Y, Shi Y, Cui Z, Luo Y, Zheng M, Chen J, Li Y, Yin Y, Wang Z (2016) Exogenous cytokinins increase grain yield ofwinter wheat cultivars by improving stay-green characteristicsunder heat stress. PLoS One 11:e0155437.

Yin XR, Xie XL, Xia XJ, Yu JQ, Ferguson IB, Giovannoni JJ, Chen KS (2016) Involvement of an ethylene response factor in chlorophyll degradation during citrus fruit degreening. The Plant Journal 86:403-12.

Yoo SC, Cho SH, Zhang H, Paik HC, Lee CH, Li J, Yoo JH, Lee BW, Koh HJ, Seo HS, Paek NC (2007) Quantitative Trait Loci Associated with Functional Stay-Green SNU-SG1 in Rice. Molecular Cells 24: 83-94.

Zhang J, Yu G, Wen W, Ma X, Xu B, Huang B (2016) Functional characterization and hormonal regulation of the PHEOPHYTINASE gene LpPPH controlling leaf senescence in perennial ryegrass. Journal of Experimental Botany 67: 935-45.

Zhang K, Gan SS (2012). An abscisic acid-AtNAP transcriptionfactor-SAG113 protein phosphatase 2C regulatory chain for controlling dehydration in senescing Arabidopsis leaves. Plant Physiology 158: 961-969.

Zheng HJ, Wu AZ, Zheng CC, Wang YF, Cai R, Shen XF, Xu RR, Liu P, Kong LJ, Dong ST (2009) QTL mapping of maize (Zea mays) stay-green traits and their relationship to yield. Plant Breeding 128: 54-62.

Zhu X, Chen J, Xie Z, Gao J, Ren G, Gao S, Zhou X, Kuai B (2015) Jasmonic acid promotes degreening via MYC2/3/4- and ANAC019/055/072-mediated regulation of major chlorophyll catabolic genes. Plant Journal 84:597-610.

Zwack PJ, Rashotte AM (2013) Cytokinin inhibition of leaf senescence. Plant Signaling and Behavior 8:e24737. 